\title{
THE ANALYSIS OF ELEMENTS GEOMETRY POSITION IN THE IRANIAN GARDEN STRUCTURE
}

\author{
Hanieh MOHAMMADI ${ }^{1, *}$, Nima VALIBEIG ${ }^{2}$ \\ ${ }^{1,2}$ Department of Architectural and Urban Conservation, Art University of Isfahan, Iran
}

Received 07 April 2017; accepted 30 August 2017

\begin{abstract}
Iranian garden has been known as a specific architecture in the whole world. Among all its special features, the geometrical structure of Iranian garden has always attracted the attention of architects and researchers. Nowadays, despite numerous studies on the Iranian gardens, the lack of geometrical studies and the extension of some old concepts have led to recognize the Iranian gardens based on a unique pattern in terms of geometry. This pattern has been known as an archetype and typifies the Iranian Garden Geometry as a quarter pattern. That it could not be a true hypothesis, because the impact of garden components on its structure has been neglected. Investigating geometric position of garden elements and their relationship with the general form of garden would provide more accurate theoretical basis for Iranian garden design. In addition, this approach could help experts to retrieve the ruined part of historical gardens. So far, extensive garden studies have been carried out more on the symbolic concepts, components introduction and typology according to times and locations. This article is the first attempt to study each common element's geometry to realize how the spatial structures could be effective in the garden formation. This paper aims to recognize the architectural geometric logic of gardens based on library studies and field recordings.
\end{abstract}

Keywords: Iranian garden, garden geometry, elements geometry, garden architecture, historical garden.

\section{Introduction}

Culture and identity in a society can be represented in the architecture and the meanings intertwined with it. In this sense, the architecture and design are the interface for transferring meaning and identity to the nation and future generations. Iranian gardens, or Persian gardens, have evolved through the history of Persian Empire concerning the culture and beliefs of the society. Moreover, because of hot and dry climate of Iran and lack of sufficient water for plantation coverage, the importance of Iranian's art in making gardens becomes noticeable.

Iranian garden has been known in art history for its specific style and identity. Over the recent decades, principles of Iranian garden formation have been the main topic of many studies. In this case, various factors have been mentioned for the causes of garden creation and formation and its special geometry, such as the four sacred elements or directions, heaven allegory, economic and fertility aspect of an Iranian garden, climate reasons and governing power. Each of these reasons has considered one aspect of gardening causes while none of them has been proven for a certain reason (HeydarNattaj \& Mansouri, 2009). The multiplicity of interpretation theories of the garden and its structural features indicates the lack of understanding geometry in gardening. This paper seeks to address the gap in the research on Iranian gardens by identifying the use of geometric shapes for symbolic meaning." The research's fundamental belief is that the straight-line shapes with the axes and regular planting patterns have been created based on logical systematic and deep interaction between garden architecture and geometry. This study tries to draw conclusions from metaphors and extended concepts, which only accept a certain pattern over Iranian gardens and concentrate on the common structural elements and their geometric influences on the garden's form. The necessity of research would be appeared when it is understood that the lack of knowing geometry elements has caused a lot of damage due to garden conservation and intervention. The comparison of historians' writings with existing samples indicates possible changes in the garden structures, especially during the Qajar era. As a result, Iranian garden

*Corresponding author. E-mail: h.mohamadi191@yahoo.com 
recognition would be impossible only based on written sources and evidence, outside of knowing the component geometrical relationship. Therefore, the key question in the present investigation is as follows:

- Is it possible to imagine a single geometric pattern for all Iranian gardens?

- What is the most influential element in the formation of the Iranian garden?

\section{Literature review}

So far, most researchers have studied Iranian garden from the following perspectives:

There are many explanations about a well-known garden in the descriptive, historical manuscripts and books of Orientalists (Clavijo, 2009; Flandin, 1967; Chardin, 1988).

Some researchers have studied the literary aspects and their relationship with Iranian gardens (Hanaway, 1976; Alemi, 2009; Ghayoumi Bidhendi, 2008).

A number of researchers have paid attention to the symbolic concepts and analyzed the garden from the semantics perspective (Hobhous, 2003; Porter \& Thevenart, 2004).

Some specific books have mentioned plant species, medicinal plants and their benefits and planting methods (Bahrami, 1961; Abu Nasr Heravi, 1755).

Some of them have considered and introduced the various parts and components of Iranian gardens (Monshizadeh, 2017; Moalemzadeh Ansari, 2015; Haghshenas, 2014; Shahcheraghi, 2012; Masoudi, 2003; Pirnia, 1994).

Some others have categorized Iranian gardens according to their region or location or paid attention to a special gardens or special cities (Monshizadeh, 2017; Mansouri, Daneshdoust \& Abouei, 2017; Ahmadi, 2016; Nasrabadi, Pourjafar \& Taghvayi, 2016; Golipour, 2014; Daneshdoust, 1990; Arianpour, 1977; Wilber, 1962).

Another group has carried out some research in several areas such as plan, function, typology and terminology of gardens (Gholipour \& Heydar Nattaj, 2016; Alaei, 2016; Shahcheraghi, 2012; Heydarnataj, 2009; Abolghasemi, 1995; Pirnia, 1994).

This article is focused on one researcher's writings and statements, and his descriptions of structural orders in gardens (Pirnia, 1994). Because he was the first and only person who explained the form of garden's elements in detail. It also draws from the study of another researcher who quoted some his description has been used (Memarian, 2010). More broadly, historical discussions must be taken into account, despite the fact that the main aim of this study is typology based on geometry. Therefore, this study considers Iranian garden in general, regardless of a particular historical period.

\section{Materials and methodology}

In this research, due to recognizing the geometrical orders of Iranian gardens, the common elements of gardens have been studied according to library evidence and scholarly viewpoints (Pirnia, 1994; Memarian, 2010), by using descriptive-analytic methods and with physical and structural point of view. After said analysis, further recognition of elements is made by drawing and graphical expression. Then various combinations of these elements are discussed. Also to draw from case studies, field studies have been used to make more accurate models based on precise recording. In this way, the geometric order among Iranian garden's elements have been reviewed and compared by authors. Statistical population was the Iranian historical garden and samples were taken by considering the most diverse structures and most harmony with the population. In terms of validity, selected samples have the least intervention, so their original and primary form has the most resemblance to their current form. The reliability of the results confirmed by interviewing old gardeners that their information proved the conducted analyses.

\section{Geometry in Iranian garden}

To describe the geometric structure of the Iranian garden, it could be said that the garden is shaped in the form of square or rectangular, based on the water volume which could be provided from that land. From the distant past, geometric structures have been associated with agriculture and farming. Some researchers believe the root of word "hendese" is "andaze," 2 and in Pahlavi language the word geometry has been "Zamig Peymane" where Zamig means land and "Peymane" means dimension (Mahdizade, Tehrani \& Valibeig, 2010). In addition, from the semantic point of view, the Latin word "geometry" means the measurement of land; its main root returns to measurement necessity and land survey for agricultural uses. Since humans started to farm and invented the plough to prepare soil, he experimentally achieved this geometric principle through the realization that the easiest way to plough the land is to move in the straight and parallel direction (Shahcheraghi, 2012, p. 43). Maybe the same principle shaped the Iranian garden geometry based on square and rectangular form due to organize and manage the garden area. On the other hand, the clear dimensions, precise lines, distinguished angels, rectangular surfaces, bright and rhythmic discipline of independent spaces and geometric composition could be attributed to the Aryans establishment in Iran (Abolghasemi, 1995, p. 281). Generally, two principals were remarkable: tree protractions beside each other and dividing the garden into squares, which were divided into smaller squares. The main part of the garden was the one-fifth of the garden's width, which includes pavilion, main road and central "kart"3 (Figure 1) (Pirnia, 1994, p. 4).

\footnotetext{
1 The Iranian meaning of geometry

2 The Iranian meaning of dimension

3 Each of almost equal section of a farm or garden
} 


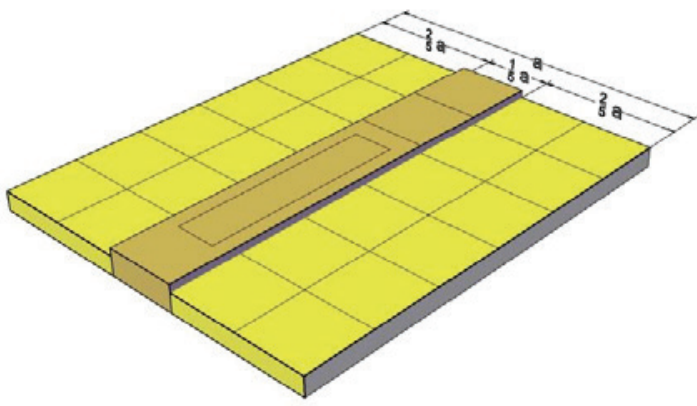

Figure 1. General division of garden (source: authors)

The overall geometry of an Iranian garden cannot be isolated from its element's geometry. Iranian gardens enclosed in a rectangular fence and the established order and spatial organization of various elements is affected by the geometric orders of gardens. Therefore, the geometric basis of gardens should be recognized, according to the geometry of its individual components.

\section{Garden elements}

All components in the garden with their geometrical system integrate the physical system of gardens. The most recognized garden components are pavilions, entrance gate, main axis, kart, streams and pools. Moreover, in some gardens, there are other elements such as external garden which was more public, like "Behesht Ayin" in a Dolatabad garden of Yazd, or service buildings such as bathroom, stall, warehouse, or summer and winter living based on climate. However, in order to not alter the garden space, this kind of building has been located outside the fence (Mirfendereski, 2004, p. 10). Therefore, the role of these elements are exempt from analysis when considering the geometric system of gardens and only the main and common elements of most gardens should be considered. In the following, each of these elements has been analyzed.

\subsection{Pavilion}

In Iranian garden architecture, the pavilion was the main building, which was built in various places inside the garden. For instance, sometimes this main building was in the middle of the garden and could be seen from all four sides and the ancillary building was located around it. Alternatively, the main building was on one side and the ancillary ones around were located with two intersections, with the main landscape along the longitudinal axis of the garden. In some gardens, the pavilion was in the middle one-third of the main axis and the inner building was put on the private garden side, with the main landscape was in the opposite direction of that. Usually, the size of garden pavilions was approximately 12 to 20 meters and the largest ones such as circular or octagonal pavilions were 25 meters (Pirnia, 1994, p. 4). In some gardens, the pavilion had a view to garden and in some others that had views on each of its four sides. For example, the pa- vilion of "Ghadamgah" garden had four façades and was opened toward four directions. Generally, pavilions follow the four-porch pattern and sometimes they had a pattern based on central symmetry. Thus, they have a tow perpendicular axis such as the pavilion of Shiraz's "Jahan nama" garden (Memarian, 2010, p. 436). Since the most common geometric forms of the pavilions were octagonal and square, the octagonal pavilions have been considered as the common pattern in the drawn samples.

\subsection{Entrance gate}

Other influential elements in Iranian garden geometry are the entrance gate. Each garden had a portal building that served as the entrance gate. This part was similar to the outer part of historical houses where the guests were welcomed. Garden entrance can be described as follows: firstly, to enter the garden one must pass "Kone" , and then enter to vestibule, one must pass through a doorway or corridor. In front of the entrance portal was closed and one or two corridors accessed into the garden from the vestibule (Memarian, 2010, p. 432). Based on this definition, the entrance gate could be drawn as in Figure 2. A historical example of this entrance type is clearly visible in "Naranjestan-e- Ghavam" garden (Figure 3). If a garden had no entrance building, a "pars" could be made against its portal. "Pars" 5 was a kind of wall, which closed the garden view from outside (Memarian, 2010, p. 432).

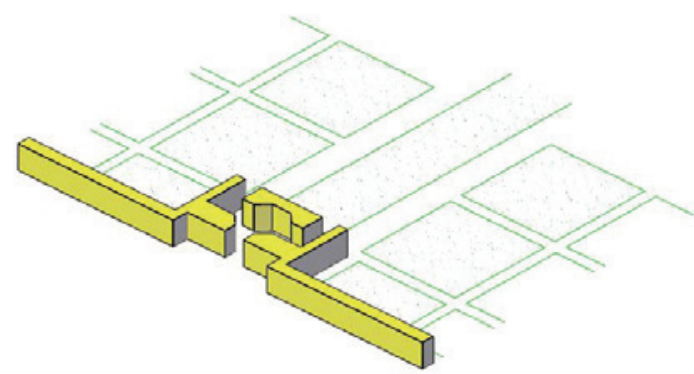

Figure 2. Entrance gate (authors)

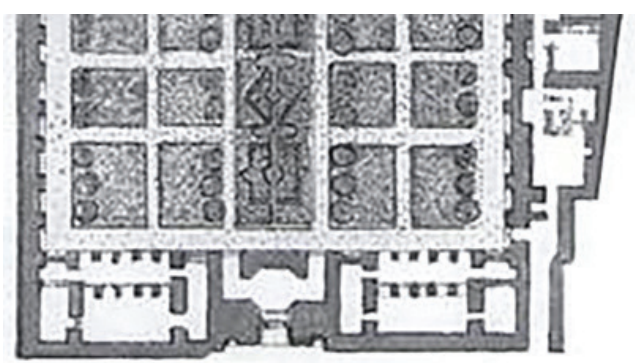

Figure 3. Entrance gate of Naranjestan-e-Ghavam (Naima, 2011, p. 111)

\footnotetext{
4 A kind of building which closed the garden view from outside

5 A kind of wall which closed the garden view from outside
} 


\subsection{Main axis in front of the pavilion}

One of the influential principles of Iranian gardening was the main view in the form of a stretched rectangle. In the garden, there was an open and stretched space, which was exactly located in the main outlook (central Kart). In this space, there were no tall trees, usually some kinds of plant were planted which were not tall and not block the garden view while they were always beautiful. This plant usually

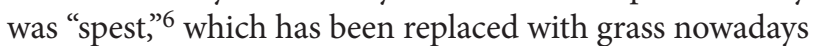
(Pirnia, 1994, p. 2). Sometimes a water-view was placed instead of a central Kart, like at Fin (Kashan) and Chehelsotoun (Behshahr) garden. The water-view was often a type of stream that was built against the drought lands and to make the water pleasant. The depth of these streams is approximately 80 centimeters and their width is about 80 centimeters (Memarian, 2010, p. 437). In some gardens, a big pool was built instead of water-view and a central Kart, like at Chehelsotoun garden of Isfahan (Pirnia, 1994, p. 5). The façade and pool proportions were different in various gardens. For example, if there was a pool in front of the pavilion, the dimensions of the pools were chosen in a way to remain enough space for sitting around that. Often the square pool dimension has been $15 \times 15$ such as the pool of Baharestan square that has been lost. If the pool was rectangular it was often very close to square; for example, a common dimension was $10 \times 12$ (Pirnia, 1994, p. 6).

\subsection{Kart}

One of the essential elements of the garden has been the "karts," or the crofts. These have always had an effective role in defining the garden geometric system. In Iranian gardening, for normal garden divisions, the streets on both sides of the garden were coming up to the front of the main building and the square sections or the "karts" were around these streets. As mentioned earlier, the history of this principle goes back to the past when square planting was usual in Iranian agriculture and when land and water were divided into square sections (Pirnia, 1994, p. 4)

\subsection{Golzar}

In some gardens, in a special part of the courtyard, which was typically near the pavilion or sometimes instead of a pool, the flowerbed, Golzar or Golestan, was built to plant the handy flower (Figure 4). Around the Golzar, a narrow strip with a margin of 30 to 70 centimeters was built, which was named "Trishe." After that, there was a "Kharand" of brick in the shape of "kalagh par" (Pirnia, 1994, p. 9).

\footnotetext{
6 A kind of Alfalfa

7 A row of bricks on the ground next to the stream or garden laid together

8 A kind of diagonal brick laying
}

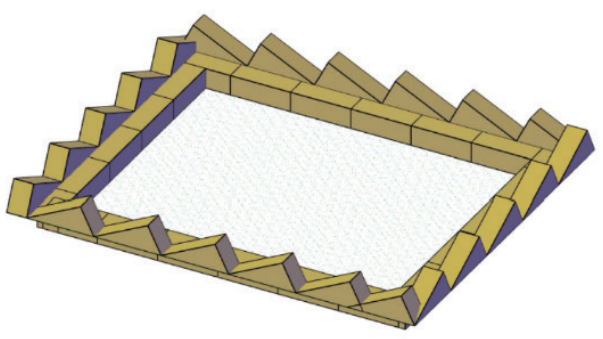

Figure 4. Golzar (source: authors)

\subsection{Kallegi pool}

Sometimes instead of the main pool, there were kallegi pools in three or all four sides of the pavilion (Figure 5). Examples can be seen at Dolatabad garden of Yazd (Memarian, 2010, p. 434).

The pools were up to $4 \times 6$, but octagonal or rectangular pools which are close to square shape were about $2.5 \times 2.5$ meters, eight corners pools have had a diameter approximately 2 to 8 meters. The eight corners pools, which were inside obtuse, have been called blunt in contrast with the pools which had a star shape and named for their sharp eight corners (Pirnia, 1994, p. 6).

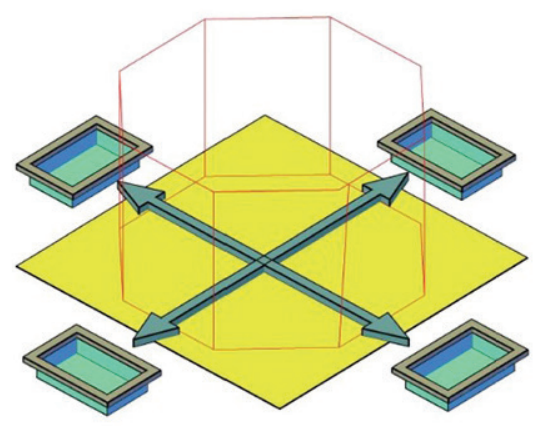

Figure 5. Kallegi pools (source: authors)

\section{Sample classification}

In the following, the article has tried to classify, draw and model the Iranian garden based on geometric definition and location of each garden element, which are previously mentioned above. Initially, garden classification has been done according to the pavilion location. In the next step, the general model for each of three element located on the main axis has been drawn as examples. The general pattern has been depicted with four Kallegi pools and Golzar in order to show where they may be present in the gardens; however, the case studies do not necessarily have Kallegi pools and Golzar, and just follow the patterns in pavilion location and the main axis elements. It should be noted that the dimensions, location and form of elements have been drawn graphically in general patterns, just to clarify the garden geometry and based on researcher descriptions (Memarian, 2010; Pirnia, 1994). 
Table 1. Garden classification based on pavilion location (source: authors)

\begin{tabular}{|l|l|l|}
\hline \multicolumn{1}{|c|}{ Categories } & \multicolumn{1}{c|}{ Pavilion Location } & \multicolumn{1}{c|}{ Main axis element } \\
\hline Category (1) & Pavilion in the middle of garden & Central kart \\
\cline { 3 - 3 } & & Water-view \\
\hline Category (2) & Pavilion in middle one third of garden & Central kart \\
\cline { 3 - 3 } & & Water-view \\
\cline { 3 - 3 } & & Pool \\
\hline Category (3) & Pavilion at the end of garden & Central kart \\
\cline { 3 - 4 } & & Water-view \\
\hline
\end{tabular}

\subsection{Pavilion in the middle of garden}

Table 2. Pavilion in the middle of garden (source: authors)

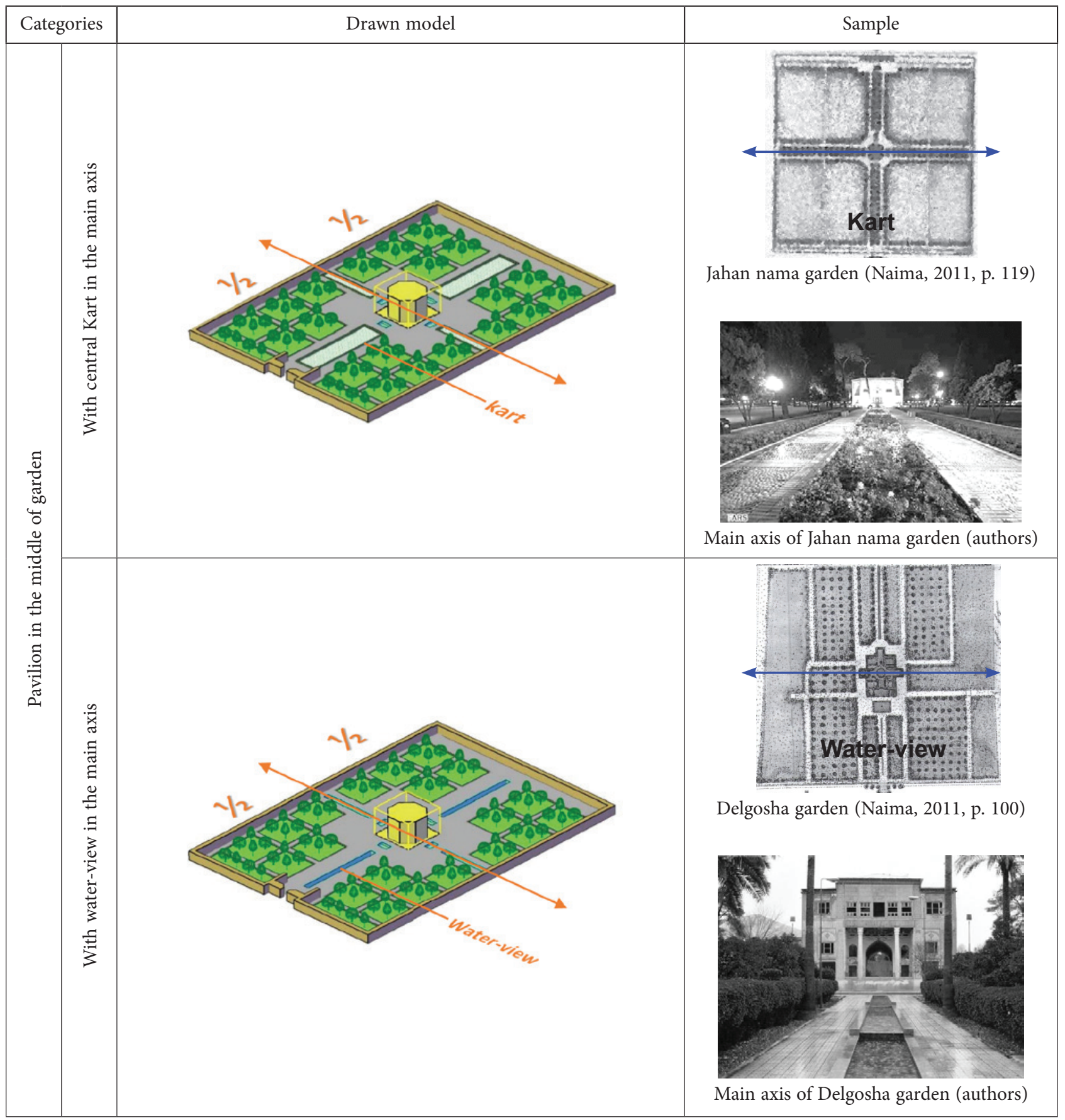




\subsection{Pavilion in the middle one-third of garden}

Table 3. Pavilion in the middle one-third of garden

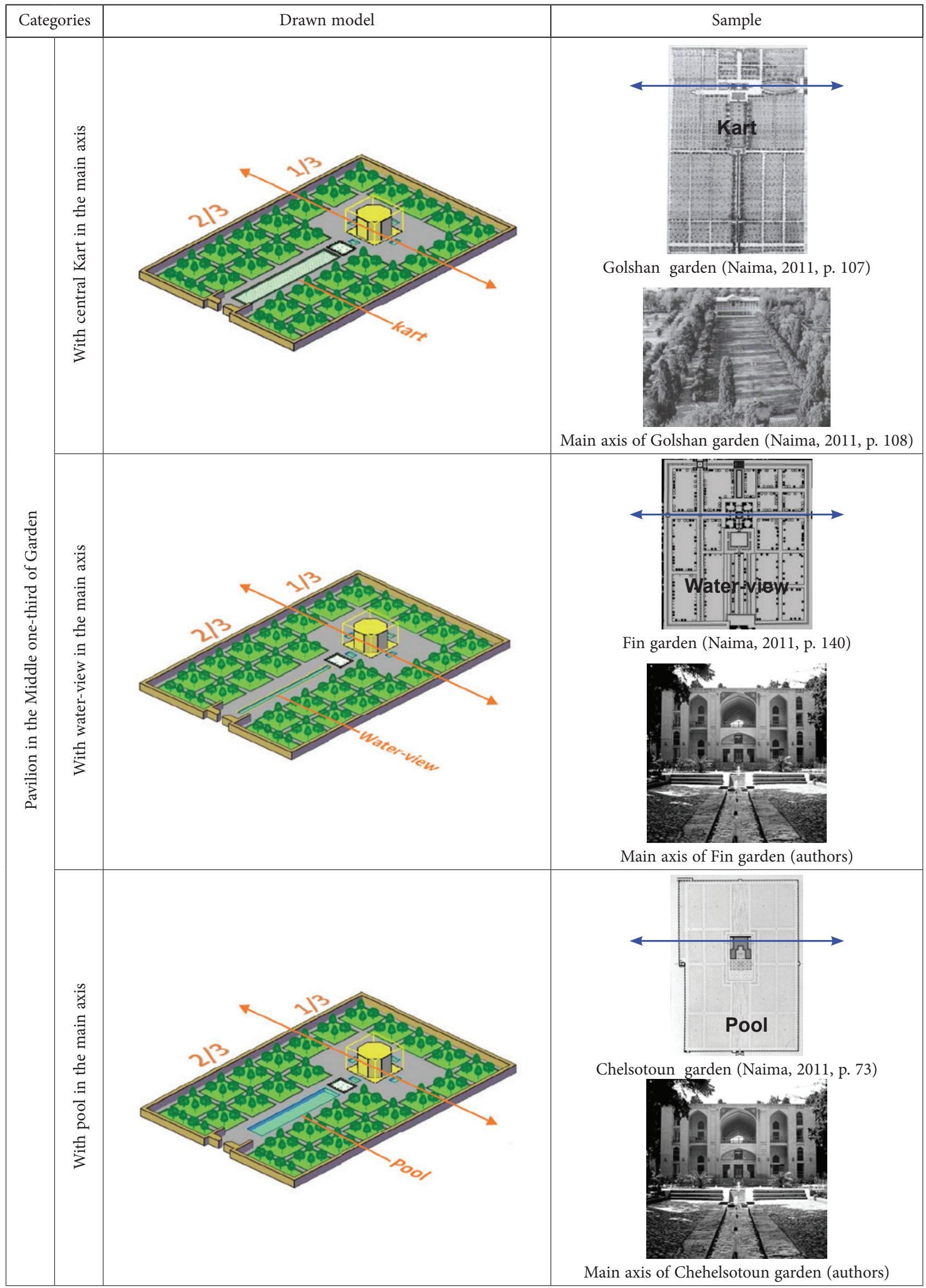




\subsection{Pavilion at the end of garden}

Table 4. Pavilion at the end of garden

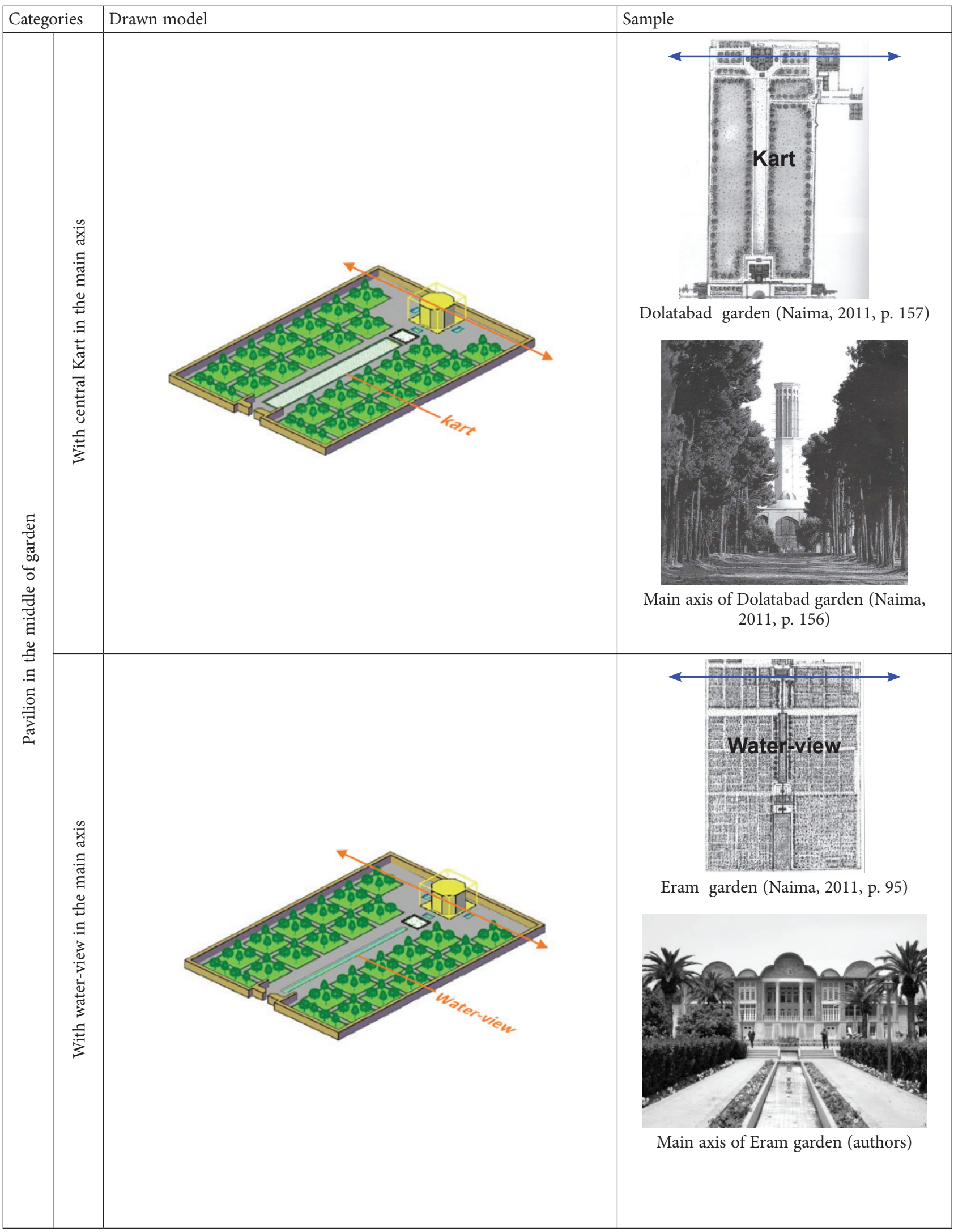




\section{Results}

Analysis reveals that the garden consists of various forms and shapes, which can be divided into three main categories, and each of these categories divided into smaller groups based on the central element on the main axis (Table 1). Therefore, it is not possible to accept a unique form as the basic and fundamental patterns for all Iranian gardens. The perpendicular and straight lines indicate the main and secondary axes in a garden. In addition, based on the straight-line geometry, each of these lines and axes define how the constituent elements should be located in Iranian gardens. The consideration of garden structure by introducing the above-mentioned elements as the common and effective ones in Iranian garden and classifying them according to Table 1 is the first step to studying the qualities of a garden, such as closeness, spatial extent, volume and geometric organization.

\section{Conclusions and discussion}

This research on the various cases demonstrates why a unique geometric pattern cannot be accepted to define the physical order of the garden. It can be stated that all the qualities and features of elemental form are effective to shape the geometry system of an Iranian garden (Table 2 to 4). As shown, Iranian gardens' architectures have combined some elements, such as the pavilion, Kart, central Kart, water-view, and pool as the integral elements, central to the garden structure. In previous studies, researchers have considered the garden geometry in too general a way. However, this article has focused on the comprehensive analysis of the garden structure based on its constituent elements. In addition, the methodology of this research could be used to study the historical garden in other climates and regions outside of Iran, as well as other elements of garden, which are not noticed in this article.

\section{References}

Abolghasemi, L. (1995, February 26-30). Persian garden norm in the history mirror. The First Congress of Architecture and Urban Planing. Tehran: Cultural Heritage Organisation.

Abu Nasr Heravi, Q. ibn Y. (1755). Guidance Alzrah. M. Moshiri (Ed.). Tehran: Tehran University.

Ahmadi, M. (2016). Chahar Bagh Avenue, Isfahan: genesis and demise. Nottingham: Nottingham Trent University.

Alaei, S. (2016). Investigation of the architecture and gardening of the Safavid era in the gardening of Ael Goli in Tabriz. Journal of Shabak, 2(4\&5), 177-187.

Alemi, M. (2009). Safavid royal garden and their relationship with city. Journal Bon, 80, 4-19.

Arianpour, A. (1977). Study the Iranian garden and the historical garden in Shiraz. Tehran: Yassavoli.

Bahrami, T. (1961). Iran's agricultural history. Tehran: Tehran University.

Chardin, J. (1988). Travels in Persia. Mineola: Dover Publications.
Clavijo, R. G. De. (2009). Embassy to Tamerlane. Translated by Guy Le Strange. London: Hardinge Simpole Limited.

Daneshdoust, Y. (1990). Tabas, the city which was (Tabas' gardens). Mashhad: Cultural Heritage and Tourism Organization.

Flandin, E. (1967). Eugène Flandin Travel literature to Iran. Tehran: Nashre eshraghi.

Ghayoumi Bidhendi, M. (2008). Khorasan Garden in Beyhaghi History. Soffe, 17(46), 5-28.

Gholipour, S., \& Heydar Nattaj, V. (2016). The impact of Timurid gardens in Samarkand on Safavid gardens in Isfahan (Chaharbagh). Bagh-e nazar, 13(40), 5-18.

Golipour, S. (2014). Regeneration of Chaharbagh Abbasi Avenue in Isfahan in Safavid and Qajar Eras with emphasis on the pictorial expressions of travelers' document. Bagh-e nazar, 11(29), 37-50.

Haghshenas, A. (2014). The importance of water bodies and structures in the Persian garden architecture. Scientific and Engineering Journal for Construction and Architecture, 4, 29-36.

Hanaway, Jr. (1976). Paradise on Earth: the terrestrial garden in Persian literature, the Islamic garden. Washington: Dumbarton Oaks.

Heydarnataj, V. (2009). Iranian garden typology. Tehran: Cultural Research Bureau.

HeydarNattaj, V., \& Mansouri, S. A. (2009). A critical study on the Chaharbagh theory in creation of the Persian gardens. Bagh-e Nazar, 2(12), 17-30.

Hobhous, P. (2003). Garden of Persia. United Kingdome: Cassel Illustrated.

Mahdizade, F., Tehrani, F., \& Valibeig, N. (2010). The use of normal triangle in mathematical calculation and geometry implementation for traditional Iranian architecture construction and building. Maremat \& Me'mari-e Iran, 1(1), 15-26.

Mansouri, S., Daneshdoust, Y., \& Abouei, R. (2017). Retrieving the original image of Bagh-e Shah of Ashraf Al-Belad (Behshahr) in different historic periods. Journal of Architecture and Urban Plannig, 17, 41-59.

Masoudi, A. (2003). Check the wall as one of the components of the Persian garden. Journal of Architecture and Culture, 5(14), 163-177.

Memarian, G. (2010). Iranian architecture. Tehran: soroush danesh.

Mirfendereski, M. A. (2004, October 15). What is Persian garden? Where is Persian garden. Proceedings of the Conference Persian garden. Tehran: Cultural Heritage Organisation.

Moalemzadeh Ansari, Sh. (2015). An investigation into water usage and water efficient design for Persian gardens. Arizona: The University of Arizona.

Monshizadeh, A. (2017). Sound-perception system of water in the Persian garden case studies: Fin and Shazdeh gardens. Journal of Architecture and Urban Planning, 9(18), 81-98.

Naima, Gholam Reza. (2011). Iranian Gardens. tehran: payam.

Nasrabadi, A., Pourjafar, M., \& Taghvayi, A. akbar. (2016). Analysis of the aesthetic role in the formation of urban space geometry in chaharbagh Abbasi. Motaleate shahri, (17), 41-54.

Pirnia, M. K. (1994). Iranian Garden. Abadi, 15, 4-7.

Porter, Y., \& Thevenart, A. (2004). Palaces and gardens of Persia. Paris: Flammarion.

Shahcheraghi, A. (2012). Pradise paradigm. Tehran: Jahad Daneshgahi.

Wilber, D. N. (1962). Persian garden and garden pavilions. Washington: Washington D.C. 